\title{
Absence of Pathogen/Host Specificity Regarding the Interaction of Bordetella Lipopolysaccharides with The Tall-Like Receptor 4 Complex Receptor
}

\author{
Wei Zhang-Sun ${ }^{1}$ and Wahib Mahana*1,2 \\ ${ }^{1}$ Department of Microbiology, University of Paris-Saclay, I2BC, Endotoxins, 91405 Orsay, France \\ ${ }^{2}$ Department of Biological Genies, University of Western Brittany (UBO), IUT, 29334 Quimper, France
}

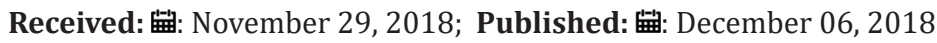

*Corresponding author: Wahib Mahana Endotoxins, Department of Microbiology, 91405 Orsay, France

\begin{abstract}
Bacterial Lipopolysaccharide [LPS] is Pathogen Associated Molecular Patterns [PAMP] recognized by the Toll Like Receptor 4 complex [TLR4MD2]. Bordetella genus of Gram- negative bacteria contains nine different species. Of them, Bordetella Pertussis [B.P] infects human and causes the whooping cough, whereas B. Bronchiseptica [B.B], infects different mammals giving respiratory disorders and finally B. Avium [B.A] infects respiratory tract of birds. The aim of this work is to study the specificity and the consequences of LPS interaction with its complex receptors among the different species of Bordetellas and their specific hosts' cells. Using a specific anti LPS antibody and three cell lines; Human THP1cells, mice Raw cells and chicken HD11 cells, we investigated the binding of the LPS from these Bordetellas to the TLR4 complex whereas LPS from E. coli [E.C] was used as a control. Cells activation was also monitored by measuring the production of three molecules; IL-6, TNF区 and nitric oxide "NO" in the supernatants of LPS activated cells. Our antibody recognized the three LPS in the ELISA assay. On the cell surface, only the B.P LPS was recognized at the three cell lines followed by B.B then B.A and E.C. Inversely, Cells activation showed that LPS from B.P was the weaker inducer of the three cytokines, whereas B.A that binds weakly to the receptor complex was the best activator of IL-6 production by these cells. Our results indicate the absence of pathogen/host specificity regarding the interaction of LPS with complex receptor.
\end{abstract}

Abbreviations: BA: Bordetella Avium; BB: Bordetella Bronchiseptica; BP: Bordetella Pertussis; ELISA: Enzyme linked immunosorbent; GAR AP: Goat Anti-Rabbit Immunoglobulin labeled with Alkaline Phosphatase; LPS: Lipopolysaccharides; MD 2: Myeloid differentiation protein 2; PAMP: Pathogen Associated Molecular Patterns; TLR4: Toll-Like Receptor 4; pNPP: p-Nitrophenyl Phosphate.

\section{Introduction}

Lipopolysaccharide [LPS] is the major components of the outer membrane of Gram-negative bacteria. It interacts with Toll-Like Receptor 4 [TLR4] to activate either dependently or independently signaling pathways of the Myeloid Differentiation 88 protein [MYD 88] and initiate the production of pro-inflammatory cytokines [1-3]. Structure of LPS is known to be heterogeneous consisting of three regions and having a variable molecular mass ranging from two to twenty $\mathrm{kD}$ [4]. Active component contains variable polysaccharide 0 specific chain region [O-antigen] specific for the species, a less variable core oligosaccharide of about 10 to 12 sugars, and a relatively conserved lipidic region called lipid A [5, 6]. Bordetella genus has an environmental origin and consists of nine species
$[7,8]$. Bordetella genus is able to colonize the respiratory tract of human and large number of animals causing variable degrees of respiratory infectious diseases ranging from asymptomatic to sever and chronic diseases [9]. Bordetella Pertussis [B.P] infects strictly human and causes whooping cough [9], B. Bronchiseptica [B.B] infects many mammals including mice and causing kennel cough in the dogs, atrophic rhinitis in the swine and snuffles in the rabbits [10-12], whereas B. Avium [B.A] infects avian causing rhinotracheitis [13]. LPS is variable in composition, biological properties, antigenicity and reactivity among the genus of bordetella [14-17]. Recognition and interaction of LPS with its receptor TLR-4 is crucial to initiate the innate immune response against 
bortedellosis and other enterobacteriaceae [18]. The interaction of LPS withTLR-4 receptor involves at least three molecules at the cell surface, CD14 binds LPS and transfers it to myeloid differentiation protein 2 [MD-2] which binds to TLR-4 and induces polymerization and signal transduction [19-21]. Additional molecules such as heat shock proteins and chemokine receptors could participate with the complex receptor to induce signaling pathways [22].

At the same time LPS is the major surface molecule and the primary virulence factor of Gram-negative bacteria [4]. A modification of its structure may regulate its various activities allowing the survival and adaptation of bacteria inside the host. To investigate this possibility, we examined the binding of LPS from three Bordetella pathogens [B.P, B.B, and B.A] to the cell surface TLR-4 complex receptor of three cell lines, human THP1, mice Raw and chicken HD 11. We also monitored the LPS activation of the cells by measuring the production of three soluble molecules IL6, NO and TNF $\alpha$, using the LPS from E. coli [E.C] as a control. Our results showed that only the B.P LPS binds correctly to the surface of three cells, followed by B.B then B.A and then E.C LPS. Inversely to the binding, we observed that B. A LPS as well as the E.C LPS are the best inducer of IL- 6 and TNF $\alpha$ in both THP1 and Raw cell lines, followed by B.B then B.P LPS. For NO, the results were dependent on the cell line. Our results demonstrate the absence of specificity between the bacterial LPS and the host complex receptor.

\section{Materials and Methods}

\section{Sera, Antibodies and LPSs}

Mouse, human, chicken and bovine sera are from GE Healthcare [Velizy, France]. Anti-LPS rabbit polyclonal antibodies were purified from rabbit serum immunized with LPS coupled to KLH using sepharose-protein A column [Thermo Fisher Scientific- France]. Serum was diluted with PBS then incubated in the column for 15 minutes, washed extensively with PBS and the bound antibodies were eluted using a glycine-HCL buffer [0.1M, PH2.5]. Five mg of purified antibodies were labeled with EZ-Link biotin LC-Hydrazide according to the manufacturer's recommendation [Thermo Fisher Scientific- France]. Goat anti rabbit immunoglobulin labeled with alkaline phosphatase [GAR-AP] [Clinisciences, Paris]. LPSs from B. Pertussis, B. Bronchisptica, B. Avium and from E. Coli 0119 were purified in our laboratory using lyophilized bacteria. The purity of LPS was checked by SDS-page and silver staining as previously described [8]. LPS was labeled with biotin-LC-hydrazide as described [23].

\section{Cell Culturing and Stimulations}

Three cell lines were used; The human monocytic cell line, THP1 obtained from Dr. J. Falla- Angel, University of Metz, the mouse monocyte-macrophage cell line Raw 264.7 was purchased from the European Collection of Cell Cultures [ECCAC, Salisbury, UK] and HD11 chicken macrophage cell line was kindly donated by Dr. E. Bottreau, INRA Nouzelly- Tours, France. All cell lines were maintained in RPMI 1640 medium supplemented with 10\% heat inactivated fetal bovine serum, $100 \mathrm{IU} / \mathrm{ml}$ penicillin and $100 \mu \mathrm{g} /$ $\mathrm{ml}$ streptomycin. Cells were incubated at $37^{\circ} \mathrm{C}$ in humid air with $5 \% \mathrm{CO}_{2}$. To optimize the conditions, fetal bovine serum was mixed either with human serum for THP1cell line, mice serum for Raw cell line and chicken serum for HD11 cell line. TLR-4 knockout splenic cells and normal splenic cells were kindly donated by Dr. E. Garciade-Paco [IBBMC, Orsay].

Cells [2X105/well] were placed in 96 well polystyrene flat bottom plate and incubated with different LPS at the indicated concentrations and time points. The supernatants were then harvested and kept frozen at $-200 \mathrm{C}$ until use for cytokine titration. Samples were assayed in triplicates and the data were reported as the concentration of tested cytokines. The SEM was less than $10 \%$ in all cases.

\section{Enzyme-Linked Immunosorbent [Elisa] Assay}

Indirect ELISA: LPS coated 96 microtiter plates [ $1 \mu \mathrm{g}$ of LPS per $\mathrm{ml}$ in $0.1 \mathrm{M}$ carbonate- bicarbonate buffer [pH 9.6]] were saturated with Phosphate-Buffered Saline [PBS] containing 0.1\% Tween 20 and $1 \%$ gelatin [PBS-T-G], washed and incubated with anti LPS antibodies at different concentrations for $1 \mathrm{~h}$ at $37^{\circ} \mathrm{C}$. After washing, the plates were incubated with Goat Anti-Rabbit immunoglobulin labeled with Alkaline Phosphatase [GAR-AP] for another h at 370C. The enzyme activity was developed using p-Nitrophenyl Phosphate [pNPP] substrate and the optical density was measured at $405 \mathrm{~nm}$ on Multiskan EX, ELISA reader [Labsystemes France].

Competitive Test: The $50 \%$ fixation point of our anti-LPS antibody bound to the LPS immobilized on the polystyrene plates was determined by the indirect ELISA described above. The antibody was then incubated at this concentration with decreasing concentrations of soluble LPS for $1 \mathrm{~h}$ at $37^{\circ} \mathrm{C}$. The mixture was then allowed to react for $1 \mathrm{~h}$ at $37^{\circ} \mathrm{C}$ with LPS-coated plates. After washing, antibodies bound to the plates were measured as described above.

Sandwich ELISA: Rabbit anti LPS antibody coated plates [1 $\mu \mathrm{g} / \mathrm{ml}$ in carbonate-bicarbonate buffer] were washed, saturated with PBS-T-G, and then incubated with different concentrations of the different LPS in PBS-T-G for $1 \mathrm{~h}$ at $37^{\circ} \mathrm{C}$. After washing, they were incubated with biotinylated rabbit anti-LPS antibody and the reaction was developed as described above, using alkaline phosphatase-conjugated streptavidin [Sigma, France].

Cell surface ELISA: The test was applied according to the method described by Grunow R et al. [24] with few modifications. Microplates 96 wells V bottom were saturated with PBS containing $10 \%$ bovine serum and $0.02 \%$ sodium azide [ $200 \mathrm{ml} /$ well]. After washing with PBS, $75 \mathrm{ml}$ of cells suspension [2X105 cells/well] in PBS with $1 \%$ bovine serum and $0.2 \%$ sodium azide were placed in the well and $75 \mathrm{ml}$ of LPS was added and incubated for one $\mathrm{h}$ at $37^{\circ} \mathrm{C}$. Then the plates were centrifuged at $1500 \mathrm{RPM}$ for 10 minutes and the supernatants were removed by flicking out the fluid phase 
and tapping slowly the inverted plates on a paper towel to discard the residual fluid. The plates were washed three times by the same way using $250 \mathrm{ml} /$ well of PBS. After washing, $100 \mathrm{ml}$ of anti-LPS antibody was added and incubated for one $\mathrm{h}$ at $37^{\circ} \mathrm{C}$ followed by second cycle of three washings. After, $100 \mathrm{ml}$ of GAR-AP was added for another $h$, then washed as above and the reaction was developed by adding $200 \mathrm{ml}$ of pNPP substrate and incubated for 30 minute at room temperature. $150 \mathrm{ml}$ of substrate was removed to a new flat-bottomed plate and the absorbance was measured as described above. To confirm the binding of LPS to the cell surface, biotinylated B.P LPS was incubated with the three cell lines for $1 \mathrm{~h}$, after washing a solution of alkaline phosphatase-conjugated streptavidin was added for $1 \mathrm{~h}$, followed by the substrates. All tests were done in duplicate and the data were reported as the main of optical density or percentage of inhibition of tested antibody. The SEM was less than $10 \%$ in all cases.

Cytokine Titration: Tumor necrosis factor-alfa [TNF- $\alpha$ ] and interleukin-6 [IL-6] present in culture supernatants of LPS activated cell lines were measured by specific sandwich enzyme-linked immunosorbent assay [ELISA] according to the manufacturer's instructions [eBioscience, San Diego, CA]. Nitric Oxide [NO] production was estimated by measuring the nitrite concentration of the cell supernatants by the Griess reaction as described in [25]. All samples were tested in triplicate and the data were reported as the concentration of tested cytokines. The SEM was less than $10 \%$ in all cases.

\section{Results}

\section{LPS reactivity with the Antibody}

LPS recognition by our antibody was measured by the indirect ELISA assay. LPS from Bordetella genus was recognized in the same order of magnitude as described in Figure 1A. LPS from $E$. coli, which was used as a control in all tests, had a few reactivity with our antibody. Sandwich ELISA assay showed the same results using the same antibody for capture as shown in Figure 1B. To ascertain the specificity of the reaction, a competitive ELISA test was performed between the soluble and plate fixed LPS. The results confirmed the specificity of our antibody and the $50 \%$ of inhibition ranges between 4 and $1 \mu \mathrm{g}$ for the three Bordetella LPS as shown in Figure 1C. For E. coli LPS, the inhibition test was inconclusive due to weak binding.

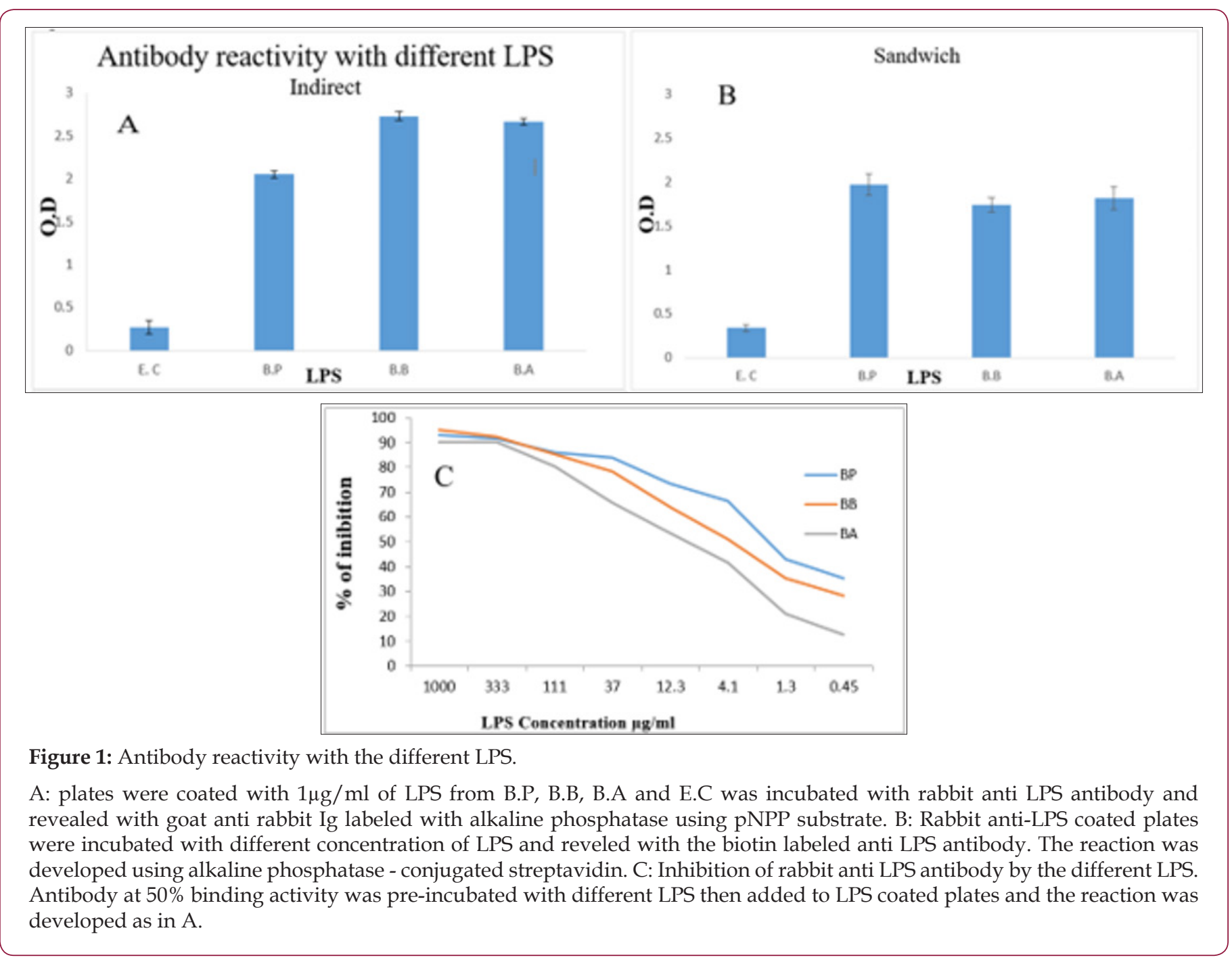

Cite this article: Wei Zhang-Sun, Wahib Mahana. Absence of Pathogen/Host Specificity Regarding the Interaction of Bordetella Lipopolysaccharides with The Tall-Like Receptor 4 Complex Receptor. Biomed J Sci \& Tech Res 11(5)-2018. BJSTR. MS.ID.002157. D0I: 10.26717/ 


\section{LPS Recognition on The Cell Surface}

The same antibody was used to visualize the binding of the LPS from different strains of bacteria on the cell surface. To choose the optimal concentration of LPS, a preliminary test using LPS at different concentration [0.01 to $30 \mu \mathrm{g} / \mathrm{ml}$ ] were incubated with the cells. After extensive washing the bound LPS was revealed by the antibody. The LPS concentration at $1 \mathrm{mg} / \mathrm{ml}$ was chosen for further evaluation. Result in Figure 2A showed that LPS from BP88 was the best one for binding to its complex receptor on the cell surface, followed by the LPS from BB. LPS from BA and from control E. coli had a little ability to bind to the cell surface complex.
The binding of the LPS to the cell surface was independent from the cell type. BP LPS binds strongly to its complex receptor on the three tested cell lines. To verify the specificity of the interaction of LPS with its TLR4 complex receptor, LPS was tested for its binding on the cell surface of splenic cells from TLR4 knockout mouse and from normal mouse. The result in Figure 2B showed no binding on the cells from knockout mouse. In addition, the role of the serum elements was tested by mixing fetal bovine serum with human $A B$ serum for THP1 cell line, mice serum for Raw cell line and chicken serum for DH11 cell line. No significant differences were observed for each cell line [data not shown].

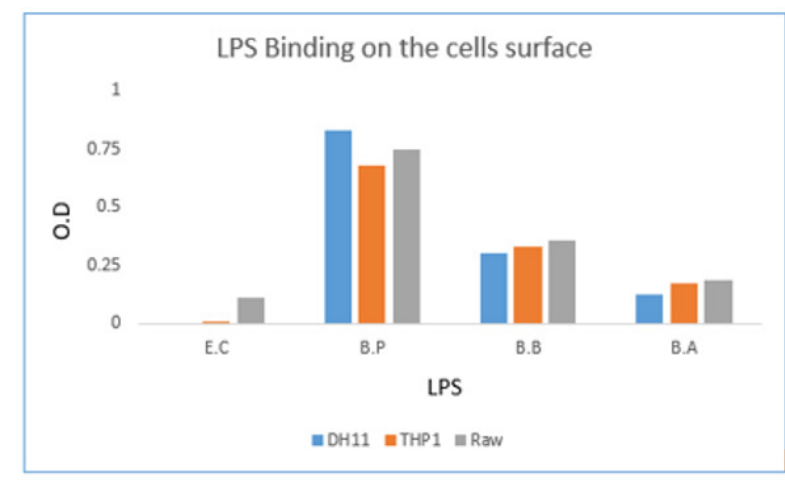

A

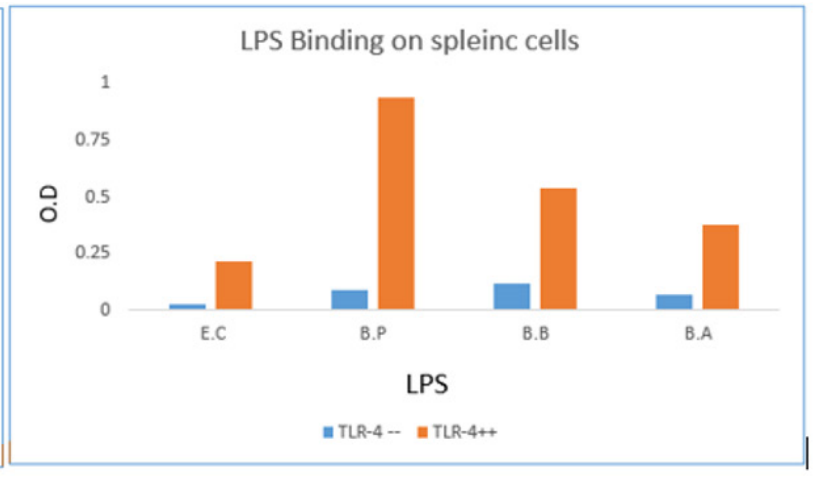

B

Figure 2: LPS binding on the cell surface.

A: LPS from different Bordetella and E.C at $1 \mu \mathrm{g} / \mathrm{ml}$ was incubated with the different cell lines, then reacted with rabbit anti LPS antibody and goat anti rabbit Ig labelled with alkaline phosphatase and the reaction was developed using pNPP substrate. B: LPS binding on splenic cells from TLR4 knockout (TLR--) and TLR4 positive cells (TLR++). Cells were incubated with LPS for one $\mathrm{h}$ and incubated with rabbit anti-LPS antibody and goat anti-rabbit Ig labelled with alkaline phosphatase.

\section{Cells Activation and Cytokines Production}

The activities of LPS on cytokine production depend on the origin of the LPS and time of incubation. To determine the appropriate concentration and the time of incubation, a preliminary test was performed. The three cell lines were incubated with different concentrations of LPS and for different incubation times; $6 \mathrm{~h}, 12 \mathrm{~h}, 24 \mathrm{~h}, 48 \mathrm{~h}, 72 \mathrm{~h}, 138 \mathrm{~h}, 144 \mathrm{~h}$ and one week. After this, the supernatants were removed for measuring the levels of cytokines and for assessing the viability of the cells. According to these preliminary results, we used different concentrations of LPS: $10 \mathrm{ng}$ for E.C and $80 \mathrm{ng}$ for Bordetella LPS of B.P, B.B and B.A. and the Time of incubation was adjusted to $24 \mathrm{~h}$ and the levels of these molecules TNF $\alpha$ IL-6 and NO were measured.

In addition, the role of the serum used in these tests was evaluated. The results of the cytokines production showed no significant differences either in presence of absence of the specific sera. The major finding indicates a slight but not significant amelioration in the Raw cells activated with B.A which showed the highest augmentation of the NO production in the presence of mouse serum as demonstrated in Figure 3. Results in Figure
3A showed the production of Nitric Oxide [NO] by the three cell lines. For Raw cell line, we found that BA, EC and BB LPS produced comparable amounts of NO ranging from 2.5 to 3 times more than the amount produced by BP. The results for THP1 cell line showed significant difference between E. coli LPS and LPS from BB and BA, which produced two times more NO than BP. However, HD11 cell lines showed differential patterns E.C and B.B LPS produced four times more NO than B.P and B.A LPS. For IL- 6 production, we found that Raw cell line produced more IL- 6 than THP1 cell line in response to all LPS tested, and that BA LPS was the best inducer of the IL- 6 followed by E.C and BB LPS. In contrast, B.P LPS had a very week activity in inducing IL- 6 production by the two cell lines Figure 4B. THP1 cells produce lower amounts of IL-6 in response of all LPS, whereas B.A and E.C LPS induced similar production, followed by BB. The results of TNF $\alpha$ shown in Figure 4C confirmed the fact that Raw cell line responds better than THP1 cell line. E.C, B.B and B.A LPS produced comparable amounts of TNF $\alpha$, which was significantly higher than the amount produced by the BP LPS. For THP1, we observed that E.C LPS was the best inducer of TNF $\alpha$ by this cell line, BA and BB had relatively the same production of TNF $\alpha$, and BP LPS induced low TNF $\alpha$ production. 


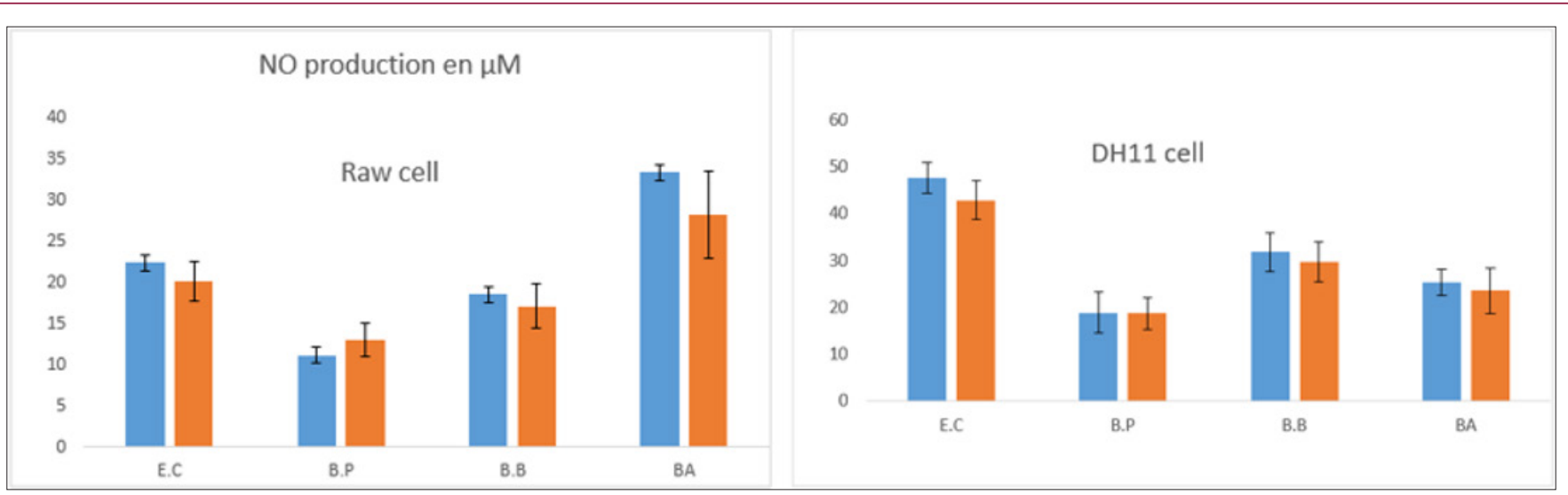

Figure 3: Role of specific serum on the production of NO by stimulated cells. Cells were incubated with different LPS at the concentration of $10 \mathrm{ng}$ for E.C LPS and $80 \mathrm{ng}$ for Bordetella LPS in presence (bleu) or absence (orange) of 5\% mouse serum for Raw cell line or $5 \%$ chicken serum for DH11 cell line for $48 \mathrm{~h}$. The concentration of NO was measured in the supernatants as described in materials and methods.

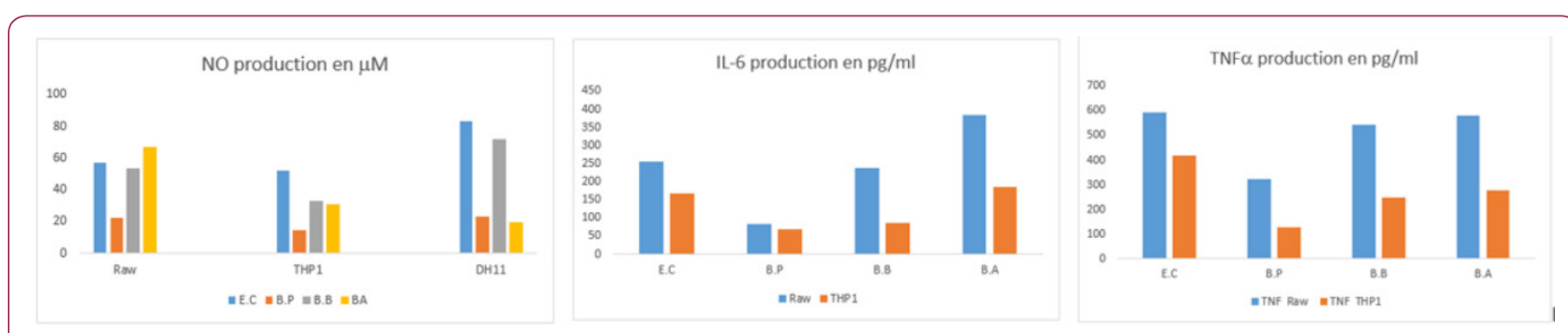

Figure 4: Cytokines production by activated cells. Raw, THP1 and DH11cell lines were incubated with different LPS at 10 ng concentration of for E.C LPS or $80 \mathrm{ng}$ for Bordetella LPS during $24 \mathrm{~h}$ of culture. After the indicated times the supernatants of activated cells were harvested and the concentration of cytokines was determined as described in materials and methods.

\section{Discussion}

In this report, we presented for the first-time results indicating the absence of specificity between the pathogen and its host regarding the interaction of LPS with the TLR4-MD2 complex receptor. Using LPS from three Bordetellas; B.P, the agent of wooping caugh, B. B, the agent of many infections in mice and other mammals, B. A, agent of respiratory infections in birds and as a control the LPS from E. coli. The LPS from the three Bordetella were recognized strongly by our antibody in the different ELISA tests; Direct, sandwich and competitive, which confirms the specificity of this antibody. In contrast, this antibody recognized differently the LPS on the cell surface of the three cell lines isolated from human, mice and chicken. It is plausible that this recognition may be due to the amount or the orientation of LPS fixed on the cell surface. The specificity of pathogen/host interaction was studied at two levels in this report. First is the binding of LPS to the TLR4 complex receptor and the second is the ability to induce the production of three soluble molecules. The specificity of the binding of LPS to TLR4-MD2 complex receptor on the cell surface was supported by the absence of the signal using the spleen cells from TLR4 knockout mice.
The Lipid A moiety is the biologically active part of LPS molecule able to activate the innate immune response $[5,6,26]$. It is not exactly known how the recognition of LPS is by the TLR4MD2 complex in birds. However, in human and mouse the E. coli lipid A is recognized in similar way by both complex receptor TLR4-MD2 [27,28]. Crystallography studies looking to understand the interaction between LPS and its TLR4-MD2 complex receptor was done using purified molecules. In our study, we used purified LPS and antibody but on the other side, we used the TLR4-MD2 complex receptor present in its natural form on the cell surface. In this situation, the test may be closer to the physiological condition and may reflect the actual complications due the involvement of different interacting factors at the cell surface. The crystal structural analysis of the LPS recognition by the TLR4-MD-2, in both human and mouse showed that the binding of LPS induces the formation of a dimer of two copies of the TLR4-MD-2-LPS [27,28]. These studies and others $[29,30]$ showed the importance of the number of fatty acid acylation in the lipid $A$ as well as hydrophobic and uncharged amino acids in TLR4-MD2. In our work, the number of acylated fatty acid on the LPS alone could not explain the difference of the binding to the cell complex receptor because the best binding was obtained with BP LPS, which has penta-acylated LPS and the other 
three LPS are hexa-acylated. However, we could not determine the binding of the E. coli LPS, which is hexa-acylated. On the other hand, the ability of different LPS to bind to the TLR4-MD2 complex receptor at the cell surface and the ability to induce the production of proinflammatory cytokines do not follow the same order. For example, LPS from BP, which had the best binding to the complex receptor is the lowest inducer of the cytokines by the three cell lines. In contrast, LPS from BA which binds weakly to the complex receptor was able to better induce the production of the cytokines. The ability to bind the complex receptor was independent from its biological activity at least in our system. These results indicate the presence of other factors influencing the binding of LPS to TLR4MD2 complex receptor and that its biological activity and lipid A alone could not be independent of two other part of the LPS.

Cytokine production after infection plays an important role in the immune response against the bacteria and decreased cytokine production due inefficient TLR4 stimulation enables bacteria to avoid host immunity [31]. Different previous studies showed the variation of LPS activity related to the structural change or to the host conditions. It has been reported that substituting the BP lipid A phosphate group with glucosamine increases the release of proinflammtory cytokines in cells expressing human but not murine TLR4-MD2-CD14 [32]. Different activity of LPS from BP and Bordetella parapertussis on human dendritic cell functions was reported and related to the CD14 dependence, cytokines production and signaling pathways activation [33]. Temperature dependent shift in the lipid A of Yersinia pestis LPS when grown at $37^{\circ} \mathrm{C}$ that differentially affects recognition by mouse versus human TLR4/MD2. LPS produced at this temperature is hypo-acylated and less stimulatory to human compared with murine TLR4/MD2 [34]. Moreover, pro-proliferation and anti-proliferation opposing effect of LPS on murine leukemia cell was reported which could be due to the increased production of IL12 [35].

The adaptation between bacteria and their hosts is a long process established during evolution, in which some specific modifications tack place in both partners. The mechanisms of such specificity are not clear, but in some cases, specificity was determined by surface receptors that allow penetration of the pathogen or their virulence factors into host tissues [36]. In our study, the three pathogens are adapted to their host i.e. BP in human, BB in mice and BA in birds. However, the interaction LPS with its complex receptor TLR4-MD2 is not specific. The three forms of LPS bind by the same way to the receptor complex on the three cells belonging to the different species, but differentially induced the production of the proinflmamtory molecules. In conclusion, our study indicates the absence of Bordetella LPS specificity for its complex receptor on the cells from the hosts and the absence of the relation between the strength of the binding to the receptor complex when correlated to its biological activity.

\section{Acknowledgement}

We thank the international office for exchange program of our university, the Agence University of the Francophonie [AUF] and the College doctoral Franco-Chinois for the financial support of Wei Zhang-Sun. We thank also E. Bottreau. E. Garcia-de-Paco and J. Falla-Angel for providing us with the cells..

\section{References}

1. Poltorak A, He X, Smirnova I, Liu MY, Van Huffel C, et al. (1998) Defective LPS signaling in $\mathrm{C} 3 \mathrm{H} / \mathrm{Hej}$ and $\mathrm{C} 57 \mathrm{BL} / 10 \mathrm{ScCr}$ mice: Mutations in TLR4 gene. Science 282(5396): 2085-2088.

2. Medzhitov R, Janeway C (2000) Innate immunity. N Engl J Med 43 (5): 338-344.

3. Lu YC, Yeh WC, Ohashi PS (2008) LPS/TLR4 signal transduction pathway. Cytokine 42 (2): 145-151.

4. Caroff M, Karibian D, Cavaillon JM, Haeffner CN (2002) Structural and functional analyses of bacterial lipopolysaccharides. Microbes Infect 4(9): 915-926.

5. Braun OH, Specht H, Luderitz O, Westphal O (1954) Studies on endotoxins of dyspepsia coli bacteria. Z Hyg Infektionskr 139(6): 565-572.

6. Darveau RP (1998) Lipid A diversity and the innate host response to bacterialinfection. Curr Opin Microbiol 1(1): 36-42.

7. Hamidou Soumana I, Linz B, Harvill ET (2017) Environmental Origin of the Genus Bordetella. Front Microbiol 24 (8): 8-28.

8. Basheer SM, Bouchez V, Novikov A, Augusto LA, Guiso N, et al. (2016) Structure activity characterization of Bordetella petrii lipid A, from environment to human isolates. Biochimie 120: 87-95.

9. Preston A, Parkhill J, Maskell DJ (2004) The Bordetella: Lessons from genomics. Nat Rev Microbiol 2 (5): 379-390.

10. Rutter JM (1981) Quantitative observations on Bordetella bronchiseptica infection in atrophic rhinitis of pigs. Vet Rec 108(21): 451-454.

11. Keil DJ, Fenwick B (1998) Role of Bordetella bronchiseptica in infectious tracheobronchitis in dogs. J Am Vet Med Assoc 212(2): 200-207.

12. Rougier S, Galland D, Boucher S, Boussarie D, Valle M (2006) Epidemiology and susceptibility of pathogenic bacteria responsible for upper respiratory tract infections in pet rabbits. Vet Microbiol 115(1-3): 192-198.

13. Kelly BJ, Ghazikhanian GY, Mayeda B (1986) Clinical outbreak of Bordetella avium infection in two turkey breeder flocks. Avian Dis 30(1): 234-237.

14. Ray A, Redhead K, Selkirk S, Poole S (1991) Variability in LPS composition, antigenicity and reactogenicity of phase variants of Bordetella pertussis. FEMS Microbiol Lett 63(2- 3): 211-217.

15. Amano K, Watanabe M, Takimoto H, Kumazawa Y (1991) Structural and biological comparison of lipopolysaccharides (LPS) from Bordetella species. Dev Biol Stand 1(73): 193-199.

16. Watanabe M, Takimoto H, Kumazawa Y, Amano K (1990) Biological properties of lipopolysaccharides isolated from Bordetella. Adv Exp Med Biol 256: 589-591.

17. Le Blay K, Caroff M, Blanchard F, Perry MB, Chaby R (1996) Epitopes of Bordetella pertussis lipopolysaccharides as potential markers for typing of isolates with monoclonal antibodies. Microbiology 142: (Pt 4): 971978.

18. Mann PB, Wolfe D, Latz E, Golenbock D, Preston A, et al. (2005) Comparative toll- like receptor 4-mediated innate host defense to Bordetella infection. Infect Immun 73(12): 8144-8152. 
19. Wright SD, Ramos RA, Tobias PS, Ulevitch RJ, Mathison JC (1991) CD14 a receptor for complexes of lipopolysaccharide (LPS) and LPS bindingprotein. Science 249 (4975): 1431-1433.

20. Chow JC, Young DW, Golenbock D, Christ WJ, Gusovsky F (1999) Toll-like receptor-4 mediates lipopolysaccharide-induced signal transduction. J. Biol. Chem 274(16): 10689-10692.

21. Nagai Y, Akashi S, Nagafuku M, Ogata M, Iwakura Y, et al. (2002) Essential role of MD-2 in LPS responsiveness and TLR4 distribution. Nat Immunol 3(7): 667-672.

22. Triantafilou K., Triantafilou M and Dedrick RL (2001) A CD14independent LPS receptor cluster. Nat. Immunol 2(4): 338-345.

23. Luk JM, Kumar A, Tsang R, Staunton D (1995) Biotinylated lipopolysaccharide binds to endotoxin receptor in endothelial and monocytic cells. Anal Biochem 232(2): 217-224.

24. Grunow R, Apuzzo DM, Wyss CT, Frutig K, Pichler WJ (1994) A cell surface ELISA for the screening of monoclonal antibodies to antigens on viable cells in suspension.J Immunol Methods 171(1): 93-102.

25. Augusto LA, Synguelakis M, Espinassous Q Lepoivre M (2003) Cellular Anti endotoxin Activities of Lung Surfactant Protein C in Lipid Vesicles. American Journal of Respiratory and Critical Care Medicine 168(3): 335341.

26. Raetz CRH, and Whitfield C (2002) Lipopolysaccharide endotoxins. Annu Rev Biochem 71:635-700.

27. Park BS, Song DH, Kim HM, Choi BS, Lee H, et al. (2009 The structural basis of lipopolysaccharide recognition by the TLR4-MD-2 complex. Nature 458(7242): 1191-1195.

28. Ohto U, Fukase K, Miyake K, Shimizu T (2012) Structural basis of speciesspecific endotoxin sensing by innate immune receptor TLR4/MD-2. Proc Natl Acad Sci USA 109(19): 7421-7426.

\section{ISSN: 2574-1241}

DOI: 10.26717/BJSTR.2018.11.002157

Wei Zhang-Sun. Biomed J Sci \& Tech Res

This work is licensed under Creative

Commons Attribution 4.0 License

Submission Link: https://biomedres.us/submit-manuscript.php
29. Resman N, Vasl J, Oblak A, Pristovsek P, Gioannini TL, et al. (2009) Essential roles of hydrophobic residues in both MD-2 and toll-like receptor 4 in activation by endotoxin. J Biol Chem 284(22): 1505215060.

30. Resman N, Oblak A, Gioannini TL, Weiss JP, Jerala R (2014) Tetraacylated lipid $A$ and paclitaxel-selective activation of TLR4/MD-2 conferred through hydrophobic interactions.J Immunol 192(4): 1887-1895.

31. Wolfe DN, Buboltz AM, Harvill ET (2009) Inefficient Toll-like receptor-4 stimulation enables Bordetella parapertussis to avoid host immunity. PLoS One 4(1): e4280.

32. Marr N, Hajjar AM, Shah NR, Novikov A, Yam CS, et al. (2010) Substitution of the Bordetella pertussis lipid A phosphate groups with glucosamine is required for robust NF-kappaB activation and release of proinflammatory cytokines in cells expressing human but not murine Toll-like receptor 4-MD-2-CD14. Infect Immun. 78(5): 2060-2069.

33. Fedele G, Nasso M, Spensieri F, Palazzo R, Frasca L, et al. (2008) Lipopolysaccharides from Bordetella pertussis and Bordetella parapertussis differently modulate human dendritic cell functions resulting in divergent prevalence of Th17-polarized responses. J Immunol 181(1): 208-216.

34. Hajjar AM, Ernst RK, Fortuno ES, Brasfield AS, Yam CS, et al. (2012) Humanized TLR4/MD-2 mice reveal LPS recognition differentially impacts susceptibility to Yersinia pestis and Salmonella enterica. PLoS Pathog. 8(10): e1002963.

35. Yu L, Zhao Y, Gu X, Wang J, Pang L, et al. (2016) Dual effect of LPS on murine myeloid leukemia cells: Pro-proliferation and anti-proliferation. Exp Cell Res 344 (2): 210-218

36. Miller SI, Ernst RK, Bader MW (2005) LPS, TLR4 and infectious disease diversity. Nat Rev Microbiol 3(1): 36-46.

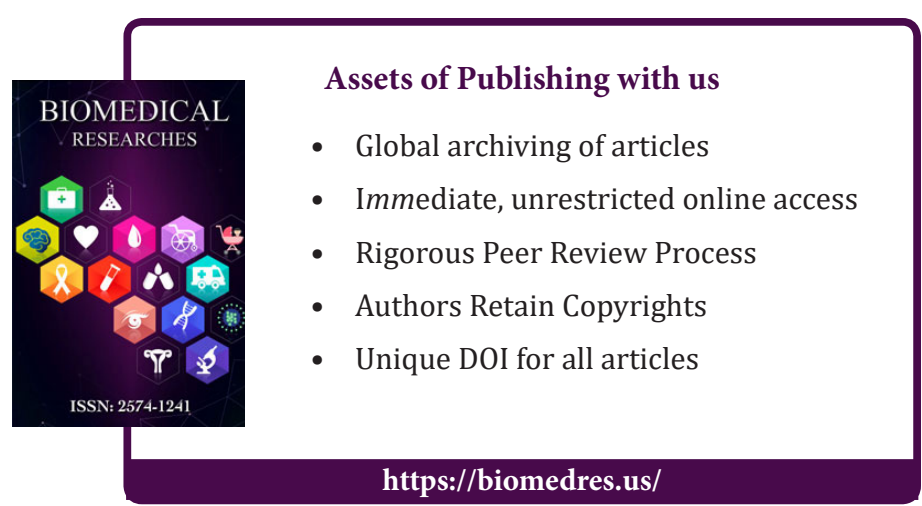

